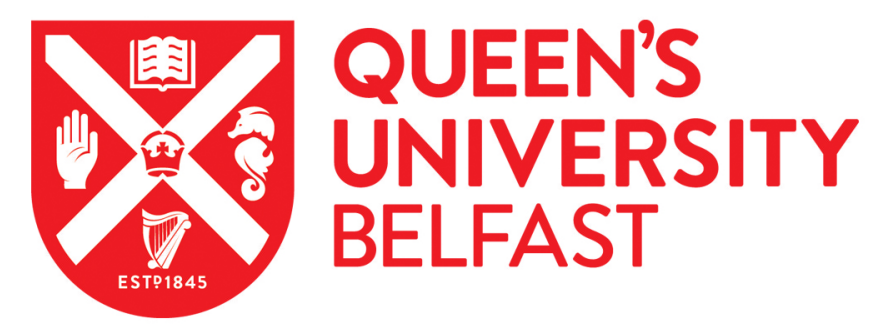

\title{
Infection-Triggered, Self-Cleaning Surfaces with On-Demand Cleavage of Surface-Localized Surfactant Moieties
}

Irwin, N., Trotter, J., Carson, L., \& McCoy, C. (2021). Infection-Triggered, Self-Cleaning Surfaces with OnDemand Cleavage of Surface-Localized Surfactant Moieties. ACS Biomaterials Science and Engineering, 7(2), 586-594. https://doi.org/10.1021/acsbiomaterials.0c01192

Published in:

ACS Biomaterials Science and Engineering

Document Version:

Peer reviewed version

Queen's University Belfast - Research Portal:

Link to publication record in Queen's University Belfast Research Portal

Publisher rights

Copyright 2021 ACS. This work is made available online in accordance with the publisher's policies. Please refer to any applicable terms of use of the publisher.

\section{General rights}

Copyright for the publications made accessible via the Queen's University Belfast Research Portal is retained by the author(s) and / or other copyright owners and it is a condition of accessing these publications that users recognise and abide by the legal requirements associated with these rights.

Take down policy

The Research Portal is Queen's institutional repository that provides access to Queen's research output. Every effort has been made to ensure that content in the Research Portal does not infringe any person's rights, or applicable UK laws. If you discover content in the Research Portal that you believe breaches copyright or violates any law, please contact openaccess@qub.ac.uk. 


\section{Infection-triggered, self-cleaning surfaces with on-demand cleavage of surface-localised surfactant moieties}

Nicola J. Irwin, Johann L. Trotter, Louise Carson, Colin P. McCoy

School of Pharmacy, Queen's University Belfast, 97 Lisburn Road, Belfast BT9 7BL, Northern Ireland, UK.

*To whom correspondence should be addressed. (Tel: +44 289097 2117; e-mail: n.irwin@qub.ac.uk)

\section{Abstract}

Biofouling of surfaces is a major cause of infection and leads to significant patient morbidity and mortality within healthcare settings. With ever-increasing concerns over antibiotic resistance and associated challenges in eradicating surface-attached biofilm communities, efficacious antifouling materials are urgently required. We herein describe the development of an inherently anti-adherent polymer system with the capacity for on-demand cleavage of surface-localised surfactant moieties. The non-ionic surfactant, Triton X-100, was linked to hydrogel monomers via hydrolytically labile ester bonds. Synthesised copolymers exhibited $\mathrm{pH}$-dependent switching of surfactant release, with elution triggered under the alkaline conditions characteristic of catheter-associated urinary tract infections, and subsequently slowed down as the $\mathrm{pH}$ decreased, representing eradication of infection. In addition, the materials demonstrated complete resistance to adherence of Staphylococcus aureus following $24 \mathrm{~h}$ incubation in infected artificial urine, with reductions in adherence of Proteus mirabilis of up to $89 \%$ also observed. This dual-pronged approach with active, infection-responsive cleavage of surfactant to enhance the anti-adherent properties of the surfactant-modified 
surfaces represents a promising self-cleaning strategy without associated concerns over bacterial resistance.

\section{Keywords}

Antifouling; surfactant conjugates; infection-responsive; $\mathrm{pH}$-triggered

\section{Introduction}

Microbial contamination of surfaces presents significant challenges in diverse fields, including healthcare, marine industries and water purification plants. ${ }^{1}$ Of particular concern is the susceptibility of biomedical devices to infection, which constitutes an increasing financial burden on healthcare systems while negatively impacting the health of patients and hindering performance of the device itself. ${ }^{2}$ At present there are no efficacious methods to prevent deviceassociated infections other than avoidance of the device itself. ${ }^{3}$ Consequently, much research has focused on the development of strategies to enhance resistance of implanted devices to infection, including the application of antimicrobial coatings. ${ }^{4,5}$ In addition to their limited efficacy in vivo, a major concern associated with the use of antibiotic-eluting materials includes the promotion of antibiotic resistance through the continual elution of potentially subinhibitory drug concentrations. ${ }^{6}$

To overcome this limitation, responsive hydrogels which selectively release drug in the presence of a defined stimulus have been developed. ${ }^{7}$ We have previously exploited the elevation of urinary $\mathrm{pH}$ reported at the onset of catheter-associated urinary tract infections (CAUTIs) with urease-producing uropathogens, such as Proteus mirabilis, as a trigger for antimicrobial release from candidate urinary catheter coatings. ${ }^{8}{ }^{9}$ CAUTIs are estimated to account for up to $80 \%$ of all hospital-acquired UTIs. ${ }^{10}$ Furthermore, the elevation of urinary 
$\mathrm{pH}$, resulting from the urease-catalysed hydrolysis of urea to ammonia triggers crystallisation of magnesium and calcium phosphates. ${ }^{11,12}$ Subsequent entrapment of these crystals within the bacterial biofilms on catheter surfaces results in recurrent episodes of catheter encrustation and blockage in $\sim 50 \%$ of all long-term catheterised patients, with increased risk of pyelonephritis and urosepsis. ${ }^{3,13}$

There has been growing interest in the use of active antimicrobial agents which avoid the selective pressure of antibiotics, thereby reducing the risk of resistance. ${ }^{14}$ Surfactants are one such class of agent which demonstrate bacteriostatic and bactericidal activities via multiple modes of action, including increasing the permeability of cellular membranes and interfering with energy production and transport via the disruption of protein structures. ${ }^{15}$ These multitarget agents therefore represent attractive alternatives to conventional antibiotics. ${ }^{16}$ In addition, the microbial anti-adherent properties of surfactant-modified surfaces containing, for example, Pluronic poly(ethylene oxide)-poly(propylene oxide) block copolymers, benzalkonium chloride and cetyltrimethylammonium bromide have been widely reported. ${ }^{17-19}$ Complementary mechanisms involved in their resistance to bioadhesion include elimination of long-range, attractive forces between bacterial cells and biomaterial substrates by the physical barrier of protruding hydrophilic chains, with short-range, repulsive, steric interactions preventing close contact of bacteria. ${ }^{20}$ Despite the numerous advantages of anti-adherent strategies, namely the avoidance of bacterial resistance promotion and systemic accumulation of active agents in potentially toxic levels, ${ }^{6}$ their inability to completely prevent bacterial adhesion and resultant limited efficacy in eradicating infection, particularly in vivo, ultimately restrict their clinical potential. ${ }^{5}$

We have developed an infection-triggered, self-cleaning strategy to enhance the bacterial resistance of surfactant-modified surfaces, without necessitating use of antibiotics. Specifically, this system combines the passive mechanisms of infection resistance displayed 
by surface-localised surfactant agents, namely osmotic repulsion and steric hindrance of bacterial interactions with the surface, with active and responsive cleavage of surfactant moieties, and associated bacteria and particulate matter, from the surface. This novel chemistry has promising potential application to reduce fouling of urinary catheter surfaces with capacity for dual-pronged attack against bacterial colonisation.

\section{Results and Discussion}

A self-cleaning, infection-triggered system was herein developed with stimuli-responsive release of surface-localised surfactant molecules to void bacteria from the surface and ultimately enhance the anti-adherent properties. This antifouling system exploits, and responds to, elevations in $\mathrm{pH}$, such as the urease-induced elevation of urinary $\mathrm{pH}$ reported at the onset of CAUTIs.

The strategy involved two synthetic steps. Firstly, dual functionalisation of the non-ionic surfactant Triton X-100 (TX) to introduce a hydrolytically labile ester bond to facilitate pHresponsive release of the surface-tethered agent and a vinyl functionality amenable to free radical copolymerisation with acrylate monomers and, secondly, copolymerisation of the surfactant conjugates with a model hydrogel comonomer, 2-hydroxyethyl methacrylate (2HEMA).

\section{Synthesis and characterisation of surfactant conjugates}

TX was covalently linked to the spacer moiety, 2-carboxyethyl acrylate, via a 4-dimethylamino pyridine (DMAP)-catalysed $N, N$ '-dicyclohexylcarbodiimide (DCC)-mediated esterification approach, the mechanism of which is shown in Scheme S1. ${ }^{21}$ The TX conjugate was isolated 
as a clear, oily residue in $94.0 \%$ yield. The structure of the molecule, as shown in Figure 1, was assigned using ${ }^{1} \mathrm{H}$ NMR spectroscopy and successful esterification was confirmed by the presence of additional bands from the 2-carboxyethyl acrylate moiety in the ${ }^{1} \mathrm{H}$ NMR spectrum of the obtained product, with the chemical shifts, splitting patterns and signal intensities expected.

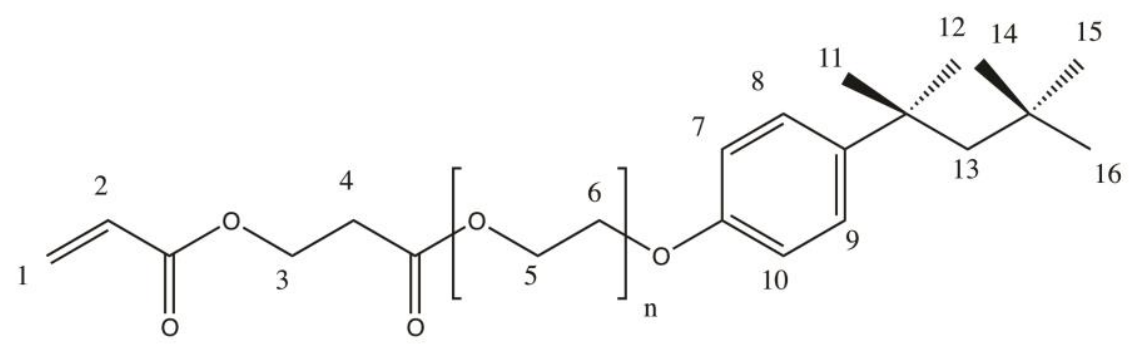

Figure 1. TX conjugate with hydrogen numbering convention.

FT-IR spectra of the starting reactants, TX and 2-carboxyethyl acrylate, and the TX conjugate are displayed in Figure S1. Successful esterification and acrylation of TX can be confirmed by the presence of new bands attributed to ester $\mathrm{C}=\mathrm{O}$ stretching $\left(1730 \mathrm{~cm}^{-1}\right)$, vinyl $\mathrm{C}=\mathrm{C}$ stretching $\left(1650 \mathrm{~cm}^{-1}\right)$ and vinyl C-H in-plane bending $\left(1408 \mathrm{~cm}^{-1}\right)$, combined with the absence of bands due to O-H in-plane bending $\left(1360 \mathrm{~cm}^{-1}\right)$ in the FT-IR spectrum of the TX conjugate in Figure $\mathrm{S} 1$ (a). As expected, bands from pyridyl $\mathrm{C}=\mathrm{C}$ stretching $\left(1610 \mathrm{~cm}^{-1}, 1575 \mathrm{~cm}^{-1}\right.$ and $\left.1510 \mathrm{~cm}^{-1}\right)$ were observed in the FT-IR spectra of both the TX reactant and the TX conjugate product. ${ }^{22}$ 


\section{Preparation and characterisation of surfactant conjugate copolymers}

The TX conjugate was copolymerised with 2-HEMA in loadings of 5\% w/w and $10 \% \mathrm{w} / \mathrm{w}$, and resulting copolymers designated as 5TXC and 10TXC, respectively (Figure S2). FT-IR spectra of the p(HEMA) homopolymer, 5TXC and 10TXC are displayed in Figure S3. The presence of the long alkyl chain of TX in the copolymers was confirmed by the increase in relative intensities of the bands attributed to symmetric and asymmetric methylene $\mathrm{C}-\mathrm{H}$ stretching vibrations $\left(2850 \mathrm{~cm}^{-1}\right.$ and $2925 \mathrm{~cm}^{-1}$, respectively) in the FT-IR spectra of the copolymers as the molar ratio of the TX conjugate was increased (Figure S3 (b)). ${ }^{22}$ Furthermore, a comparative decrease in intensities of the bands attributed to methyl $\mathrm{C}-\mathrm{H}$ asymmetric and symmetric bending at $1480 \mathrm{~cm}^{-1}$ and $1380 \mathrm{~cm}^{-1}$, respectively, in relation to the band at $1450 \mathrm{~cm}^{-1}$ attributed to methylene $\mathrm{C}-\mathrm{H}$ bending vibrations, was observed as the comonomer ratio of the TX conjugate to 2-HEMA was increased. ${ }^{23}$ The presence of the aromatic ring of TX was confirmed by the appearance of additional bands attributed to pyridyl $\mathrm{C}=\mathrm{C}$ stretching vibrations $\left(1530 \mathrm{~cm}^{-1}\right.$ and $\left.1430 \mathrm{~cm}^{-1}\right)$ in the FT-IR spectrum of 10TXC, and the relative increase in intensities of the two bands at $1620 \mathrm{~cm}^{-1}$ and $1565 \mathrm{~cm}^{-1}$, also attributed to pyridyl $\mathrm{C}=\mathrm{C}$ stretching, compared to the neighbouring band at $1720 \mathrm{~cm}^{-1}$ assigned to ester $\mathrm{C}=\mathrm{O}$ stretching, as the molar ratio of TX within the copolymers was increased. ${ }^{23}$

Importantly, the absence of bands attributed to vinyl $\mathrm{C}=\mathrm{C}$ stretching vibrations at $1650 \mathrm{~cm}^{-1}$ and $1640 \mathrm{~cm}^{-1}$, and the band attributed to vinyl C-H in-plane bending $\left(1408 \mathrm{~cm}^{-1}\right)$ in the FT-IR spectra of the copolymers confirms successful copolymerisation of the TX conjugate with 2HEMA. 


\section{Contact angle analysis}

The effect of copolymerisation with the TX conjugate on water wettability of the hydrogel was characterised by measurement of the contact angle of an air bubble on the control p(HEMA) and the 5TXC and 10TXC copolymer surfaces. The contact angles measured for the materials are shown in Table 1.

Table 1. Contact angles for p(HEMA) and the TXC copolymers

\begin{tabular}{lc} 
Polymer & Contact angle $\left(^{\circ}\right)($ Mean \pm S.D. $)$ \\
\hline p(HEMA $)$ & $55.5 \pm 3.57$ \\
5TXC & $43.5 \pm 2.80$ \\
10TXC & $36.1 \pm 2.58$
\end{tabular}

Copolymerisation with the TX conjugate caused a significant reduction in contact angle and therefore a significant increase in water wettability relative to the $\mathrm{p}(\mathrm{HEMA})$ homopolymer, with reductions of $12.0^{\circ}$ and $19.4^{\circ}$ observed for 5TXC and 10TXC, respectively. Surface hydrophobicity is a factor not only of the chemical groups present at the surface, but also their orientation and the resultant physical topography. ${ }^{24}$ Accordingly, the significant increase in surface hydrophilicity upon copolymerisation with the TX conjugate may be attributed to the outward projection of the hydrophilic poly(ethylene oxide) (PEO) chains of TX away from the hydrogel backbone. The use of surfactants for manipulation of surface wettability has been widely reported. ${ }^{25,26}$ For example, Guo et al. (2018) have recently modified the wettability of lignite surfaces through treatment with nonionic polyhydroxy and polyoxyethylene ether 
surfactants, $n$-dodecyl- $\beta$-D-maltoside and dodecyl hepta glycol, respectively. Adsorption of the polyether surfactant was found to significantly decrease the hydrophilicity of lignite in contrast to the increase in surface hydrophilicity reported upon adsorption of the polyhydroxy surfactant, as a result of coverage of the oxygen-containing functional groups of lignite with weakly polar ether groups of the former and the introduction of polar hydroxyl groups with the latter. ${ }^{27}$

\section{Equilibrium swelling}

The time-dependent swelling behaviour of the TXC copolymers in comparison to the $\mathrm{p}$ (HEMA) homopolymer after immersion of the xerogels in $\mathrm{pH} 7$ and $\mathrm{pH} 10$ universal buffers is displayed in Figures 2 (a) and (b), respectively, and the EWCs of the hydrogels at each pH are reported in Table 2.
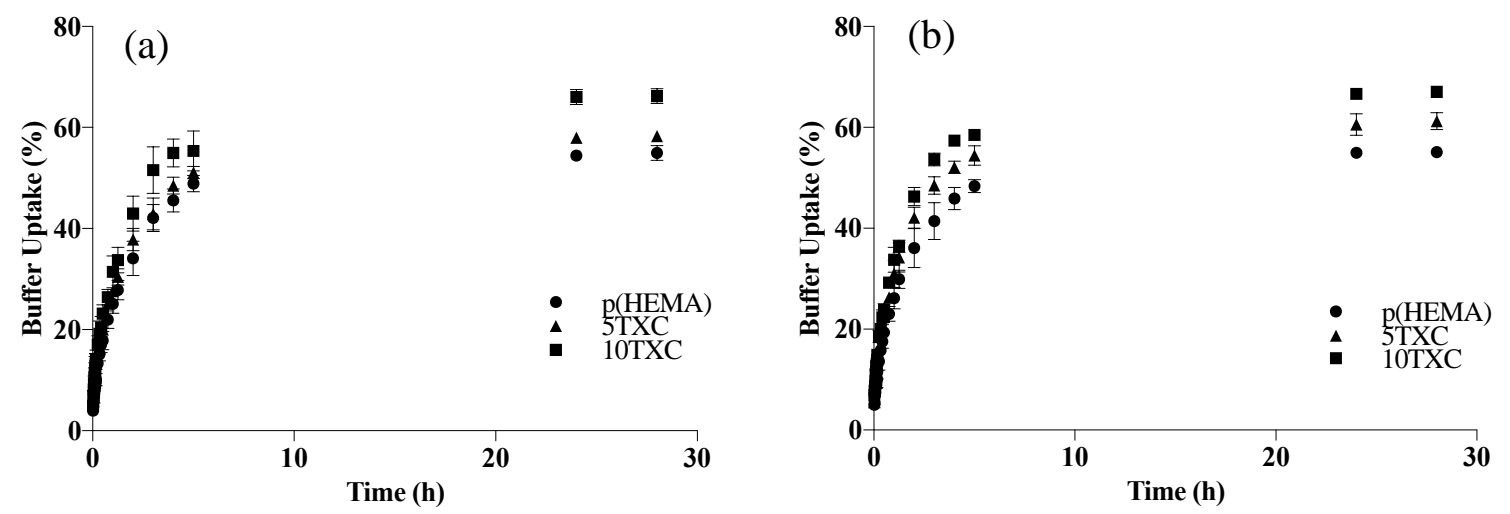

Figure 2. Time-dependent swelling behaviour (mean \pm S.D.) of $\mathrm{p}(\mathrm{HEMA})$, 5TXC and 10TXC, represented by circles, triangles and squares, respectively, in universal buffers of (a) $\mathrm{pH} 7$ and (b) $\mathrm{pH} 10$. Values displayed are the mean of five replicate measurements and error bars represent standard deviations of the mean values. 
Table 2. Equilibrium water contents of $\mathrm{p}(\mathrm{HEMA})$ and the TXC copolymers in $\mathrm{pH} 7$ and $\mathrm{pH} 10$ buffers

\begin{tabular}{llc}
\hline & EWC (\%) (Mean \pm S.D.) \\
\cline { 2 - 2 } & pH 7 & pH 10 \\
p(HEMA) & $55.2 \pm 1.1$ & $55.4 \pm 0.7$ \\
5TXC & $58.5 \pm 0.4$ & $61.4 \pm 1.8$ \\
10 TXC & & \\
& $66.6 \pm 1.3$ & $67.4 \pm 0.6$ \\
\hline
\end{tabular}

As shown in Figure 2, copolymerisation with the TX conjugate did not significantly affect the time to reach the equilibrium swollen state, with the degree of swelling of the copolymers and the $\mathrm{p}$ (HEMA) homopolymer increasing until $28 \mathrm{~h}$ of immersion in both $\mathrm{pH} 7$ and $\mathrm{pH} 10$ universal buffers, after which no further increase in weight was reported. The copolymers displayed significantly higher EWCs than the p(HEMA) homopolymer at $\mathrm{pH} 7$ and $\mathrm{pH} 10$ as anticipated, due to the influence of the surfactant conjugate on the hydrophilic character and corresponding polymer swelling capacity. ${ }^{28}$ Furthermore, no significant differences in EWCs were observed between the polymers in buffers of different $\mathrm{pH}$ values due to the absence of ionisable pendant groups. ${ }^{29}$

\section{In vitro $\mathrm{pH}$-mediated surfactant release kinetics}

Surfactant conjugates were designed such that TX would be released following ester hydrolysis, whereas the acrylate spacer would remain a key component of the copolymer backbone. The effect of $\mathrm{pH}$ on kinetics of TX release from 10TXC and a physically loaded 
counterpart, 10TXL, and the cumulative release of TX from 10TXC following successive cycles of immersion in pH 7 and pH 10 buffer solutions are shown in Figures 3 (a) and (b) respectively.

(a)

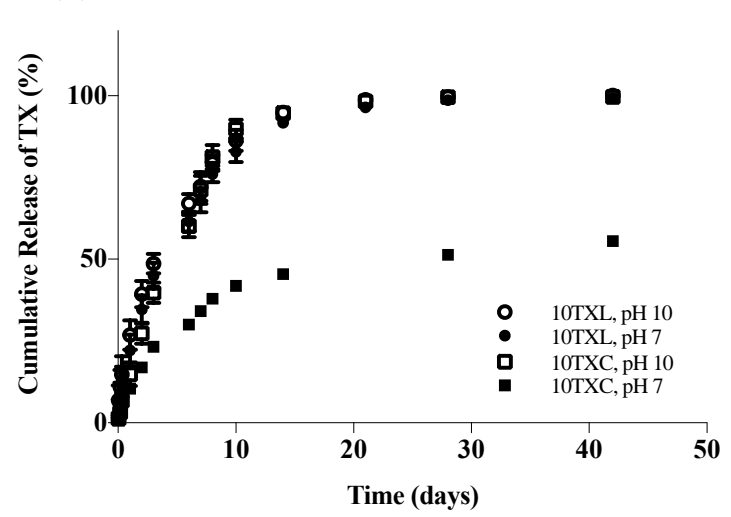

(b)

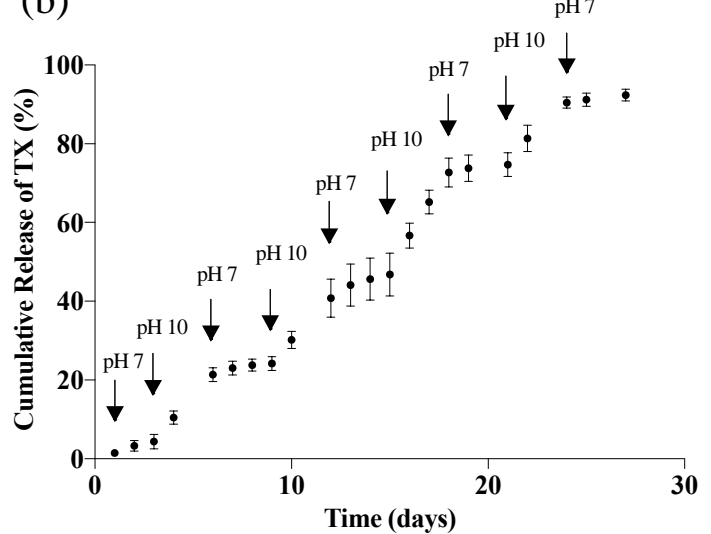

Figure 3. (a) Release of TX from 10TXC and 10TXL. Open and closed symbols refer to release at $\mathrm{pH} 10$ and $\mathrm{pH}$ 7, respectively. (b) Triggered on-off release profile of TX from 10TXC. Arrows represent the point of immersion in $\mathrm{pH} 7$ or $\mathrm{pH} 10$ buffer solutions. Sink conditions were maintained throughout the study. Values displayed are the mean of five replicate measurements and error bars represent standard deviations of the mean values.

As shown in Figure 3 (a), sustained release of TX for periods in excess of three weeks was achieved from 10TXC and 10TXL in both $\mathrm{pH} 7$ and $\mathrm{pH} 10$ universal buffers. The TX conjugate copolymers displayed a much slower rate of surfactant release at $\mathrm{pH} 7$ than at $\mathrm{pH} 10$, with the rate for 50\% release of the incorporated TX moiety from the copolymers approximately fivefold lower at $\mathrm{pH} 7$ than at $\mathrm{pH} 10$. Conjugation of $\mathrm{TX}$ via a hydrolytically labile ester bond to an acrylate spacer, prior to copolymerisation with 2-HEMA, was effective in delaying release at $\mathrm{pH}$ 7, representing normal physiological urine $\mathrm{pH}$, in contrast to the rapid release observed at $\mathrm{pH} 10$, representing the $\mathrm{pH}$ of infected urine. ${ }^{12,30}$ The significant differences in rates of 
release according to media $\mathrm{pH}$ were not, however, observed with the TX-loaded polymers, from which release proceeded at statistically similar rates at both $\mathrm{pH} 7$ and $\mathrm{pH} 10$.

Moreover, the stepped profile of the release kinetics shown in Figure 3 (b) illustrates the dependence of surfactant liberation on exposure to media of elevated $\mathrm{pH}$ in an 'on-off' fashion. During each consecutive immersion in $\mathrm{pH} 10$ buffer, the rate of TX release was accelerated. Release rates were then observed to decrease upon transfer of the samples to $\mathrm{pH} 7$ buffer. This triggered on-off release was demonstrated to be reproducible over four cycles.

The release exponents $n$ reported in Table 3 are indicative of the mechanism of release, and were determined from linear regression of data from the initial $60 \%$ cumulative release of TX fitted to the Korsmeyer-Peppas model equation (Figure S4).

Table 3. Kinetic equations and coefficients obtained from fitting $\mathrm{pH}$-mediated release data to the Korsmeyer-Peppas model

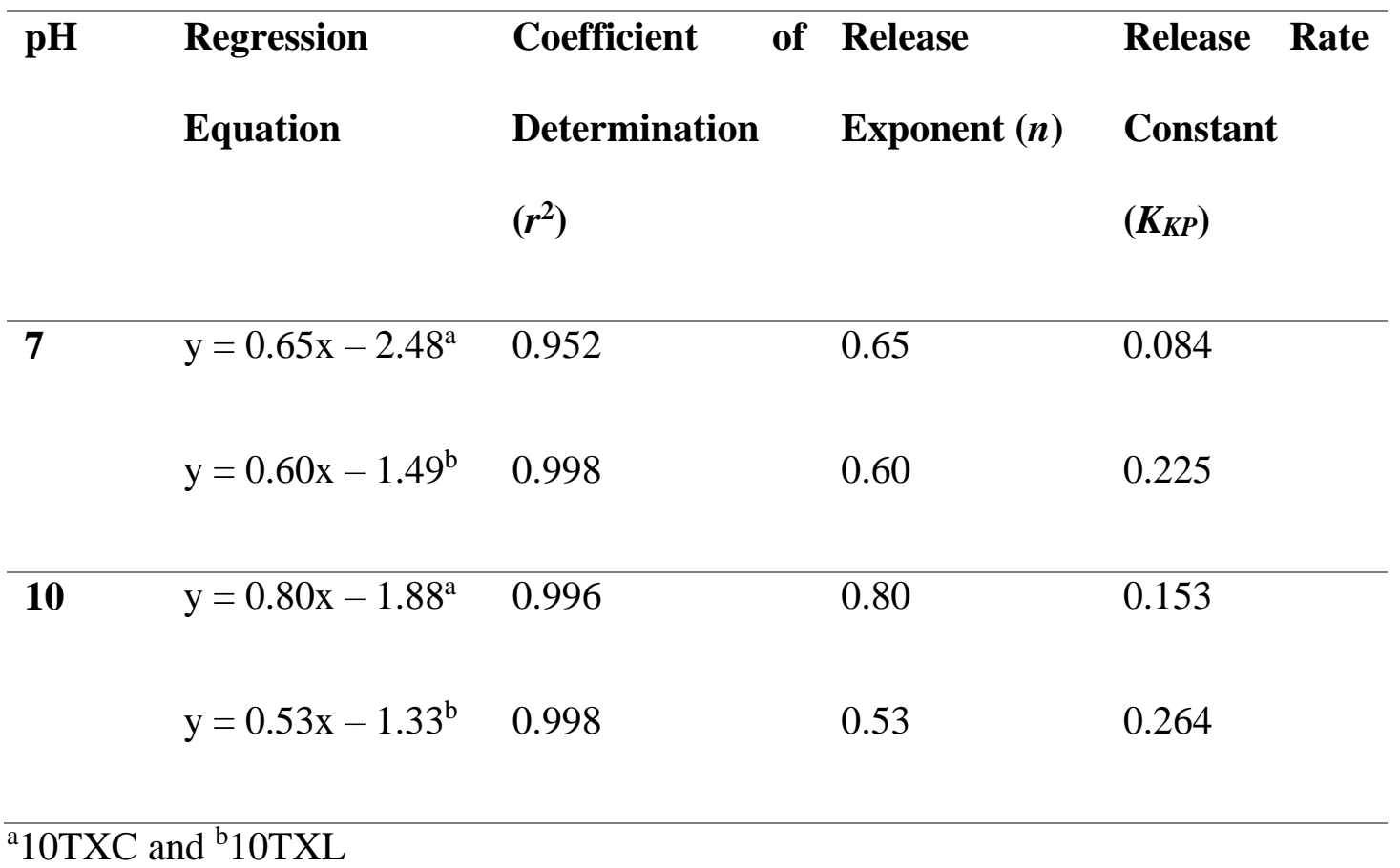


Release exponents at $\mathrm{pH} 7$ and $\mathrm{pH} 10$ from polymers physically loaded with TX approximate 0.5 and are therefore indicative of a Fickian diffusion-controlled release mechanism. The sustained release over periods of up to three weeks, as shown in Figure 3, was attributed to the high molecular weight of TX ( 647 $\left.\mathrm{gmol}^{-1}\right)$ and possible entanglements of the long PEO chains within the polymer network, effectively reducing the rate of diffusion through the cross-linked $\mathrm{p}$ (HEMA) matrix. Furthermore, the non-statistical differences in the release rate constants upon elevation of $\mathrm{pH}$ from $\mathrm{pH} 7(0.225)$ to $\mathrm{pH} 10(0.264)$ confirms the insignificant effect of $\mathrm{pH}$ on kinetics of TX release from the physically-loaded polymers. This may be explained by the absence of ionisable moieties in both the surfactant and the hydrogel matrix, and the resultant absence of $\mathrm{pH}$-dependent ionic interactions which may effectively promote or retard release, as observed with ionisable polymer networks. ${ }^{31}$

An additional factor to be considered when evaluating the release of agents covalently conjugated to a polymer network is the rate of hydrolysis of the connecting labile bonds, a prerequisite to diffusion through the polymer matrix. ${ }^{9}$ Inference as to the relative importance of these two factors in controlling the overall release of TX from the copolymers was made by comparing the release profiles of the surfactant conjugate copolymers and the physicallyloaded polymers. Release exponents for release from the copolymers were 0.65 and 0.80 at $\mathrm{pH}$ 7 and $\mathrm{pH} 10$, respectively, confirming the additional influence of the rate of ester hydrolysis in controlling release following covalent conjugation. The statistically similar rates of TX release from the copolymers at $\mathrm{pH} 10$ and the TX-loaded polymers at both $\mathrm{pH}$ values suggest that release at this elevated $\mathrm{pH}$ was predominantly controlled by diffusion of $\mathrm{TX}$ through the polymer matrix, after almost instantaneous hydrolysis of the ester bonds linking TX to the acrylate spacer. At $\mathrm{pH} 7$, however, covalent conjugation of the TX moiety to the polymer matrix effectively decoupled the rate of release from physicochemical characteristics of the surfactant and the copolymer matrix, as observed from the significantly slower rate of TX 
release in comparison to the physically-loaded polymers, with release now limited by the rate of ester hydrolysis.

\section{Bacterial adherence assay}

Fundamental to the application of the surfactant conjugate copolymers as candidate surface coatings for infection-resistant urinary biomaterials is their ability to inhibit colonisation of urinary pathogens. Accordingly, adherence of representative Gram-negative and -positive nosocomial pathogens, $P$. mirabilis and $S$. aureus, to 5TXC and 10TXC was assessed by challenging samples with inoculi of $1 \times 10^{6} \mathrm{cfumL}^{-1}$ in PBS of $\mathrm{pH} 7$ and $\mathrm{pH} 10$, and more biologically-representative artificial urine (AU) media over time periods of $4 \mathrm{~h}$ and $24 \mathrm{~h}$. The urease-producer, $P$. mirabilis, was selected since this is the main problematic urinary pathogen responsible for the major issues of recurrent catheter blockages and infections experienced by $\sim 50 \%$ of chronically catheterised individuals. ${ }^{32}$ Bacterial adherence to surfaces of the copolymers relative to the $\mathrm{p}(\mathrm{HEMA})$ control is displayed in Figure 4. 
$(\mathrm{a}, \mathrm{i})$

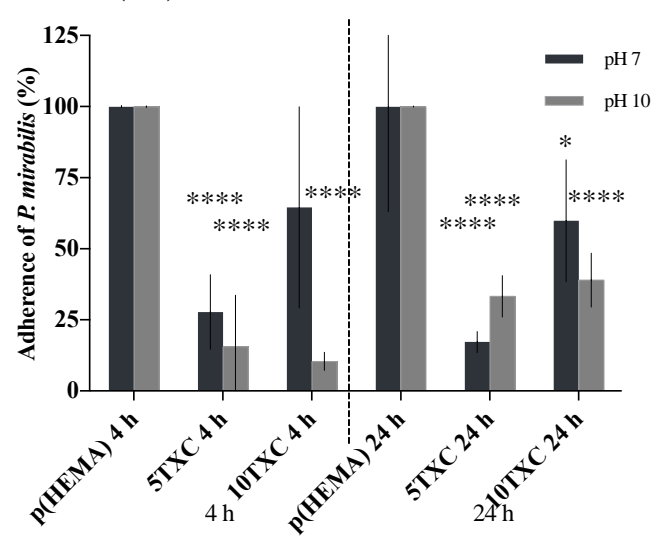

$(\mathrm{b}, \mathrm{i})$

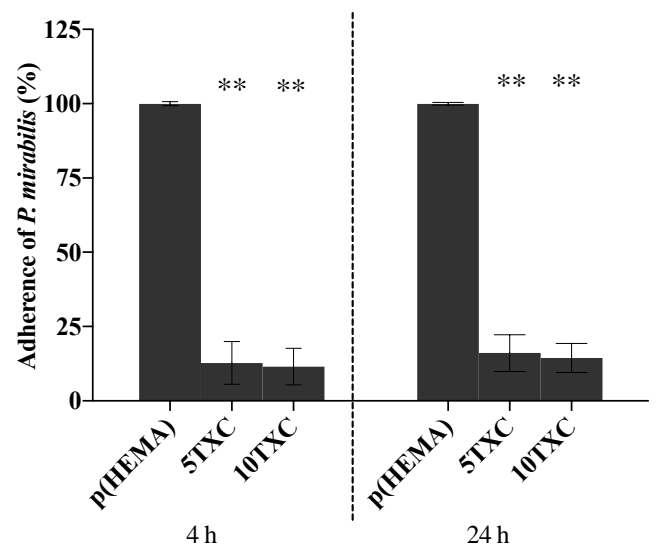

(a,ii)

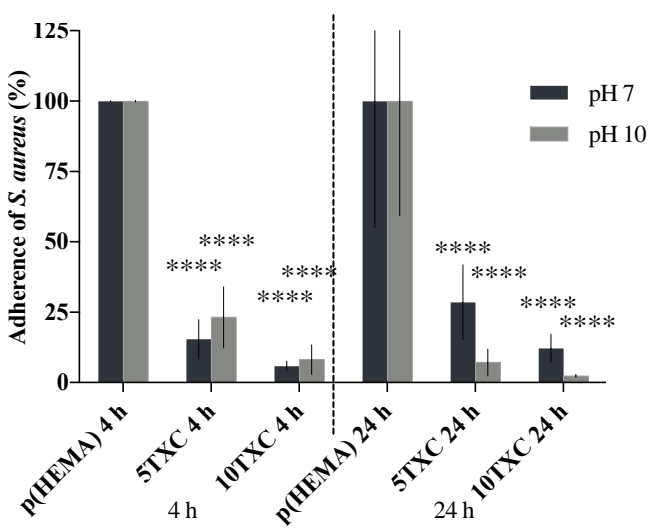

(b,ii)

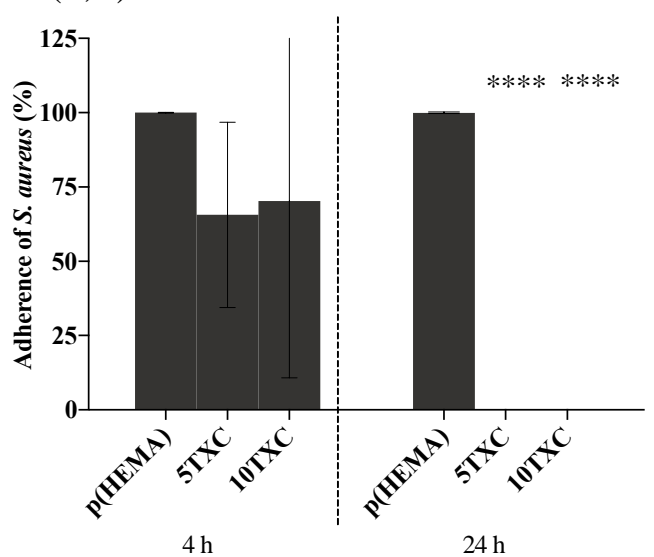

Figure 4. Adherence (\%) of (i) P. mirabilis and (ii) S. aureus to p(HEMA), 5TXC and 10TXC relative to the p(HEMA) control after $4 \mathrm{~h}$ and $24 \mathrm{~h}$ incubation in inoculated (a) TSB-containing PBS and (b) AU at $37^{\circ} \mathrm{C}$. Columns and error bars represent mean values \pm S.D $(n=5)$. Significant differences relative to the p(HEMA) control are indicated by $*$, where $*$, ** and $* * * *$ represent $p \leq 0.05,0.01$ and 0.0001 , respectively.

As shown in Figure 4 (a), reductions in bacterial adherence to the copolymers of up to $66.7 \%$ and $97.6 \%$ relative to the control were observed for $P$. mirabilis and $S$. aureus, respectively, after $24 \mathrm{~h}$ incubation in $\mathrm{pH} 10$ media. In addition, adherence of $P$. mirabilis and $S$. aureus was reduced by up to $82.7 \%$ and $87.9 \%$, respectively, at $\mathrm{pH} 7$, indicating the inherent anti-adherent properties of the surfactant-modified material. 
The surfactant molecules were attached to the hydrogel backbone via hydrolytically labile ester bonds in an effort to facilitate rapid cleavage and subsequent voiding of bacteria and associated particulate matter from the surface upon elevation of $\mathrm{pH}$. As expected, reductions in bacterial adherence to the copolymers were greater at $\mathrm{pH} 10$ than at $\mathrm{pH} 7$, with the exception of S. aureus adherence to the surfactant conjugate copolymers after $4 \mathrm{~h}$ and $P$. mirabilis adherence to 5TXC after $24 \mathrm{~h}$. Indeed, the adsorption of surfactant molecules passively leached from treated polystyrene surfaces to bacterial cells, with the subsequent formation of a steric barrier preventing their close contact with, and subsequent attachment to, the surface has previously been reported to lead to significant reductions in staphylococcal adhesion. ${ }^{17}$

The reductions in bacterial adherence observed in $\mathrm{pH} 7$ media demonstrate that the copolymer surfaces were inherently resistant to colonisation, even in the absence of the $\mathrm{pH}$ trigger when cleavage and subsequent voiding of the surfactant and associated particulate matter from the surface were minimal. The mechanism behind this suppression of bacterial adherence was attributed to the combined osmotic and entropic repulsive forces generated from surfaceprojected PEO chains, referred to as steric stabilisation, as previously reported for polymerbrush coatings. ${ }^{33,34}$

Furthermore, the copolymers were found to be more resistant to bacterial adherence within the more biologically-representative media, AU, than in PBS of $\mathrm{pH} 7$ and $\mathrm{pH} 10$, with adherence of $P$. mirabilis to 10TXC relative to the p(HEMA) control reduced by $85.6 \%$ and no observed adherence of $S$. aureus to either copolymer after $24 \mathrm{~h}$ incubation.

Comparing Figures 4 (i) and (ii), the TX conjugate copolymers demonstrated greater resistance to adherence of the Gram-positive bacterium, $S$. aureus, than the Gram-negative bacterium, $P$. mirabilis. Differences in susceptibility of Gram-positive and -negative bacteria to antimicrobials is commonly attributed to differences in the structure and composition of their 
cell walls, with the presence of a lipopolysaccharide outer membrane providing Gram-negative bacteria with additional protection from exogenous toxins. ${ }^{35}$ In addition, $P$. mirabilis possesses a suite of virulence factors including uroepithelial cell adhesins and fimbriae, which help facilitate adherence and rapid formation of biofilm. ${ }^{36}$ It is believed that the ability of $P$. mirabilis to colonise the surface of catheters is further aided by swarmer cell differentiation and migration, facilitating effective surface translocation. ${ }^{37}$

\section{Zones of bacterial growth inhibition}

Zones of bacterial growth inhibition produced by the two copolymers on MHA of $\mathrm{pH} 7$ and pH 10 are displayed in Figure 5. 

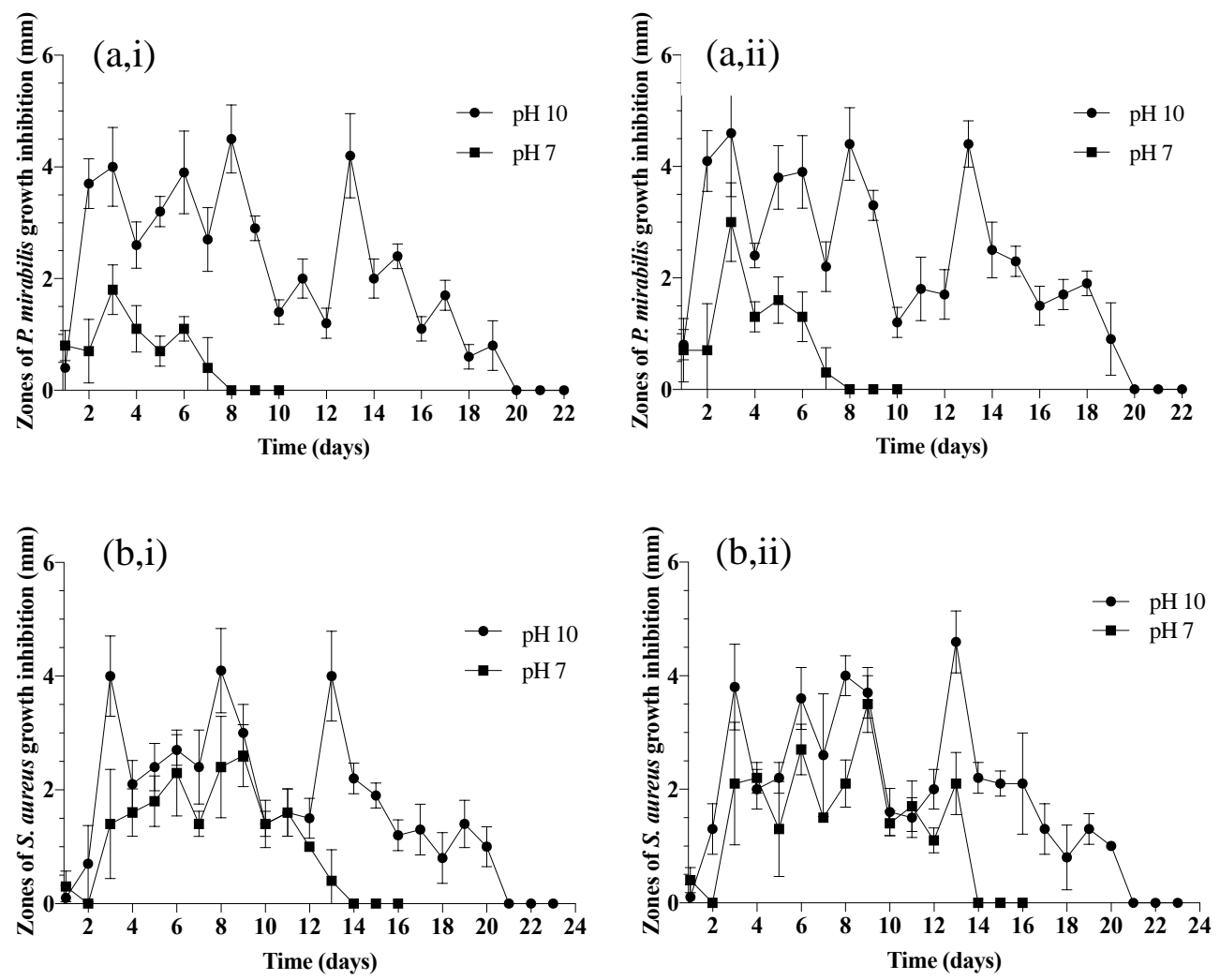

Figure 5. Zones of (a) P. mirabilis and (b) S. aureus growth inhibition around (i) 5TXC and (ii) 10TXC on MHA of $\mathrm{pH} 7$ and $\mathrm{pH}$ 10. No zones were observed around the $\mathrm{p}$ (HEMA) control therefore this has been omitted from the graphs.

Both copolymers inhibited growth of $P$. mirabilis and $S$. aureus, demonstrating the ability of surfactant to diffuse from the hydrogel and inhibit bacterial growth. Significant differences in the magnitude of the inhibitory zones and the persistence of inhibitory activity were demonstrated depending on the agar $\mathrm{pH}$ and pathogen. In contrast, no significant differences in activity were observed between 5TXC and 10TXC. Zones of $P$. mirabilis growth inhibition were observed for 7 days on agar of $\mathrm{pH}$, whereas on MHA of $\mathrm{pH} 10$ growth was inhibited for 19 days. Similarly, zones of S. aureus growth inhibition were observed for a longer duration on pH 7 agar than on pH 10 agar, with zones recorded for 13 days and 20 days, respectively. 
In addition, with the exception of zones measured after $24 \mathrm{~h}$, all $P$. mirabilis inhibitory zones were significantly larger on $\mathrm{pH} 10$ agar than the corresponding zones on $\mathrm{pH} 7$ agar during the initial seven days of contact. The larger zones of growth inhibition observed at the elevated $\mathrm{pH}$ were attributed to the significantly higher amounts of surfactant released at $\mathrm{pH} 10$ than at $\mathrm{pH}$ 7, with the zones decreasing in size and eventually disappearing when the release rates plateaued and sub-inhibitory concentrations were released.

\section{Conclusions}

The capacity of the system developed herein to rapidly trigger release of surfactant on demand by facile modulation of media $\mathrm{pH}$, as occurs during urinary catheter infections, is an exciting concept with promising potential application as infection-responsive, self-cleaning biomaterials. Importantly, the observed $\mathrm{pH}$-responsive release profiles demonstrate the accelerated rate of release when infection arises and the subsequent decrease in the release rate when infection has been eradicated. The attractiveness of this system stems not only from its ability to potentially reduce the risk of infection, but may also help circumvent the problem of antibiotic resistance.

\section{Experimental Section}

Triton X-100, 2-carboxyethyl acrylate, $N$-benzyl- $N$ '-cyclohexylcarbodiimide (99\%, polymerbound, extent of labelling: $\sim 1.3 \mathrm{mmoLg}^{-1} N$ loading), 4-dimethylamino pyridine ( $\geq 99 \%$ ), anhydrous dichloromethane ( $\geq 99.8 \%$ ), ethyl acetate ( $\geq 99.8 \%$, HPLC grade), 2-hydroxyethyl methacrylate ( $\geq 99 \%$ ), ethylene glycol dimethacrylate ( $\geq 98 \%)$, phosphoric acid, acetic acid ( $\geq 99.7 \%$ ), boric acid ( $\geq 99.5 \%)$, hydrochloric acid, potassium chloride and sodium hydroxide 
were obtained from Sigma-Aldrich (Poole, Dorset, UK). 2,2'-Azobisisobutyronitrile was purchased from VWR International Ltd. (Lutterworth, UK). Phosphate-buffered saline, Mueller-Hinton broth, tryptone soya broth and quarter-strength Ringer's solution were obtained from Oxoid Ltd. (Hampshire, UK). Phosphate-buffered saline and tryptone soya broth were adjusted to $\mathrm{pH} 10$ by addition of $1 \mathrm{M}$ sodium hydroxide solution.

Proteus mirabilis ATCC 35508 and Staphylococcus aureus ATCC 6538 were obtained from LGC Standards (Middlesex, UK) and maintained on cryopreservative beads (Protect Bacterial Preservation System, Technical Service Consultants Ltd., UK) in $10 \%$ glycerol at $-80^{\circ} \mathrm{C}$. Bacteria were cultivated in $\mathrm{MHB}$ at $37^{\circ} \mathrm{C}$ when required for the microbiological assessments.

\section{Synthesis and characterisation of surfactant conjugates}

Triton X-100 (TX) (2.19 g, $3.5 \mathrm{mmol})$, 2-carboxyethyl acrylate (0.50 g, $4.2 \mathrm{mmol})$ and 4dimethylaminopyridine (DMAP) $(0.043 \mathrm{~g}, 0.42 \mathrm{mmol})$ were added to anhydrous dichloromethane (DCM) $(50 \mathrm{~mL})$ and stirred for $10 \mathrm{~min}$. The mixture was cooled to $0^{\circ} \mathrm{C}$ in an ice bath, before the addition of $N$-benzyl- $N$ '-cyclohexylcarbodiimide (3.23 g, $4.2 \mathrm{mmol})$. After a further 30 min stirring, the ice bath was removed and the white cloudy mixture was left to stir overnight at ambient temperature with a drying tube attached. The mixture was then filtered to remove the insoluble polymer-bound $N$-benzyl- $N$ '-cyclohexylcarbodiimide and evaporated to dryness under reduced pressure to yield a clear, oily residue $(2.47 \mathrm{~g}, 94.0 \%)$.

Proton nuclear magnetic resonance $\left({ }^{1} \mathrm{H}\right.$ NMR) spectra of the two reactants, TX and 2carboxyethyl acrylate, and the synthesised TX conjugate, the structure of which is shown in Figure 1, were recorded on a Bruker Ultrashield ${ }^{\mathrm{TM}} 400$ Plus instrument operating at $400 \mathrm{MHz}$. 
Chemical shifts were recorded in parts per million ( $\mathrm{ppm}, \partial$ ), downfield of the internal standard tetramethylsilane (TMS).

NMR $\delta{ }^{1} \mathrm{H}\left(\mathrm{CDCl}_{3}\right): 6.05-6.20(\mathrm{dd}, 1 \mathrm{H}, 1 \mathrm{cis}) ; 5.80-5.98$ (dd, 1H, 1 trans); 6.36 - 6.48 (dd, $1 \mathrm{H}, 2) ; 4.38-4.50(\mathrm{t}, 2 \mathrm{H}, 3) ; 2.64-2.78(\mathrm{t}, 2 \mathrm{H}, 4) ; 3.82-3.88(\mathrm{t}, 2 \mathrm{H}, 5) ; 4.08-4.12(\mathrm{t}, 2 \mathrm{H}$, 6); $7.22-7.28(\mathrm{dd}, 2 \mathrm{H}, 7$ and 10); $6.80-6.86(\mathrm{dd}, 2 \mathrm{H}, 8$ and 9); 1.35 (s, 6H, 11 and 12); 1.70 (s, 2H, 13); 0.70 (s, 9H, 14, 15 and 16).

Fourier Transform infrared (FT-IR) spectra of the two reactants, TX and 2-carboxyethyl acrylate, and the synthesised TX conjugate, were obtained using a Jasco FTIR 4100 spectrometer with the sample pressed between two sodium chloride discs. 32 scans were recorded over the range $4000-400 \mathrm{~cm}^{-1}$ with a resolution of $4 \mathrm{~cm}^{-1}$.

\section{Preparation of surfactant conjugate copolymers}

Copolymers containing 5\% w/w and $10 \% \mathrm{w} / \mathrm{w}$ of the TX conjugate, designated herein as 5TXC and 10TXC, respectively, were prepared by dissolving EGDMA (1\% w/w), AIBN (1\% w/w) and the TX conjugate $(5 \% \mathrm{w} / \mathrm{w}$ and $10 \% \mathrm{w} / \mathrm{w}$, respectively) at ambient temperature in 2hydroxyethyl methacrylate (2-HEMA) $(93 \% \mathrm{w} / \mathrm{w}$ and $88 \% \mathrm{w} / \mathrm{w}$, respectively) with stirring. The total mass of each copolymer was $10 \mathrm{~g}$. The resulting solutions were injected slowly into moulds comprising two glass plates, which were separated with medical grade silicone tubing with lumen diameter of $0.3 \mathrm{~mm}$ and wall thickness of $0.18 \mathrm{~mm}$, lined with release liner, and clamped using spring clips. Following polymerisation at $60^{\circ} \mathrm{C}$ for $18 \mathrm{~h}$, the formed films were soaked for one week in deionised water to remove unreacted monomers and initiator, with the washing medium refreshed daily. 
A surfactant-loaded polymer containing the same molar equivalent mass of TX as the 10TXC copolymer was prepared for comparative analysis of the $\mathrm{pH}$-mediated release profiles. The corresponding molar equivalent-loaded polymer film (10 g), designated as 10TXL, was prepared from a solution of TX (0.83 g), EGDMA (0.1 g), AIBN (0.1 g) and 2-HEMA (8.97 $\mathrm{g}$ ), with the polymerisation conditions as described above. A control film of p(HEMA) (10 g) was also prepared from a solution of EGDMA (1\% w/w), AIBN (1\% w/w) and 2-HEMA (98\% $\mathrm{w} / \mathrm{w})$.

FT-IR spectra of p(HEMA), 5TXC and 10TXC were obtained using a Jasco FTIR 4100 spectrometer fitted with a diamond attenuated total reflectance (ATR) accessory (MIRacle, Pike technologies, USA) from an average of 32 scans over the range $4000-400 \mathrm{~cm}^{-1}$ with a resolution of $4 \mathrm{~cm}^{-1}$.

\section{Contact angle analysis}

Contact angles of the surfaces of the p(HEMA) homopolymer, 5TXC and 10TXC were determined via the captive bubble technique, using a First Ten Ångströms (FTA) 200 videobased contact angle analyser (Portsmouth, Virginia, USA) in combination with FTA 32 video software for image capture and analysis. Samples were placed onto a custom-built mount which was inverted and placed into a water-filled glass petri dish. An air bubble was then dispensed onto the sample surface by a curved needle and images acquired ${ }^{38}$. Ten replicates were performed for each sample.

\section{Equilibrium swelling studies}


The equilibrium degrees of swelling of 5TXC and 10TXC were examined in comparison to unmodified p(HEMA). Replicate samples $\left(10 \mathrm{~mm}^{2}\right)$ were dried in an oven at $60^{\circ} \mathrm{C}$ until constant weight, weighed and placed in $\mathrm{pH} 7$ or $\mathrm{pH} 10$ universal buffer prepared according to the formulation of Koller et al. (1992) reported in Table $4^{39}$.

Table 4. Formulation of universal buffer

\begin{tabular}{lllll}
\hline $\mathbf{p H}$ & Stock $(\mu \mathrm{L})^{\mathbf{a}}$ & $\mathbf{2 M ~ N a O H}(\mu \mathrm{L})$ & $\mathbf{K C l}(\mathbf{m g})$ & $\mathbf{H}_{2} \mathbf{O}(\mathbf{m L})$ \\
\hline $\mathbf{7}$ & 833 & 437 & 25.8 & 11.4 \\
$\mathbf{1 0}$ & 714 & 557 & 0 & 11.4
\end{tabular}

a Stock solution $(100 \mathrm{~mL})$ contained $2.7 \mathrm{~mL} \mathrm{H}_{3} \mathrm{PO}_{4}, 2.29 \mathrm{~mL} \mathrm{AcOH}$ and $2.48 \mathrm{~g} \mathrm{H}_{3} \mathrm{BO}_{3}$ dissolved in deionised $\mathrm{H}_{2} \mathrm{O}$.

At designated intervals, samples were removed, blotted with filter paper to remove excess surface water and reweighed, as previously described ${ }^{8}$. Samples were returned to the buffer media and soaked until no further increase in mass. The weight percentage of buffer within the swollen polymer, designated as the equilibrium water content (EWC), was calculated according to equation $1^{40}$.

$$
\operatorname{EWC}(\%)=\left(M_{\mathrm{f}}-M_{\mathrm{i}}\right) / M_{\mathrm{i}} \times 100 \quad \text { [Equation 1] }
$$


Where $M_{\mathrm{f}}$ and $M_{\mathrm{i}}$ represent the final sample mass after water absorption and the initial dried sample mass, respectively. EWCs were determined in quintuplicate for each polymer.

\section{In vitro pH-mediated surfactant release kinetics}

Kinetics of TX release from 10TXC and 10TXL were examined at $\mathrm{pH} 7$ and $\mathrm{pH} 10$ in universal buffer solutions. Pre-swollen discs $\left(10 \mathrm{~mm}^{2}\right)$, suspended on a needle, were placed in McCartney bottles containing $10 \mathrm{~mL}$ prewarmed universal buffer solution ( $\mathrm{pH} 7 \mathrm{or} \mathrm{pH} 10)$ and shaken at $37^{\circ} \mathrm{C}$ in an oscillating water bath $(100 \mathrm{rpm})$. At predetermined intervals, the discs were transferred to fresh medium to ensure sink conditions. The released surfactant was quantified by UV-visible spectroscopy (BMG Labtech FLUOstar Omega $(\lambda=279 \mathrm{~nm})$ with MARS software), with concentration dependence of TX on absorbance determined from calibration curves prepared using universal buffer of the appropriate $\mathrm{pH}\left(r^{2}>0.999\right)$, as previously described ${ }^{9}$. Release experiments at each $\mathrm{pH}$ were performed in triplicate.

The mechanism of drug release at each $\mathrm{pH}$ was determined by fitting data from the initial $60 \%$ cumulative release of TX to the Korsmeyer-Peppas power law model (equation 2).

$$
F=K_{\mathrm{KP}} t^{n}
$$

[Equation 2]

Where $F$ is the fractional drug release in time $t$ and $K_{\mathrm{KP}}$ represents the release rate constant ${ }^{41}$, 42.

In addition, the ability of surfactant release from the TX conjugate copolymers to be triggered in an on-off fashion was assessed by placing discs in prewarmed $\mathrm{pH} 7$ buffer for three days, 
then transferring to $\mathrm{pH} 10$ buffer for three days, and then back to $\mathrm{pH} 7$ buffer, with UV-visible spectroscopic analysis at $279 \mathrm{~nm}$ performed throughout. Five replicate samples were analysed.

\section{Bacterial adherence assays}

Overnight broth cultures of P. mirabilis ATCC 35508 and S. aureus ATCC 6538 in MHB were centrifuged (3000 rpm, 12 min) and re-suspended in either PBS (pH 7) supplemented with $0.5 \%$ TSB (pH 7) or PBS (pH 10) supplemented with 1\% TSB (pH 10), with the turbidity of suspensions adjusted to $\mathrm{OD}_{550}$ values equivalent to an approximate inoculum density of $1 \times 10^{8}$ cfumL $^{-1}$. A 1 in 100 dilution was then performed in PBS supplemented with $0.5 \%$ TSB of the

relevant $\mathrm{pH}$, and inoculum densities verified by viable count. Replicate discs (10 mm diameter) of 5TXC and 10TXC, and p(HEMA) as control, were placed into individual wells of a 24-well flat bottom tissue culture plate (Corning Inc., NY) and completely immersed with aliquots of bacterial suspension $(1 \mathrm{~mL})$ with density of $1 \times 10^{6} \mathrm{cfumL}^{-1}$. Plates were continuously shaken in an orbital incubator at $37^{\circ} \mathrm{C}$. After designated time intervals of $4 \mathrm{~h}$ and $24 \mathrm{~h}$, the samples were removed from the bacterial suspension using sterile forceps and washed three times in QSRS to remove any non-adherent bacteria. Samples were then sonicated for $10 \mathrm{~min}$ in QSRS and vortexed for $30 \mathrm{sec}$ to remove adherent bacteria. Viable counting was performed by the Miles and Misra serial dilution technique, followed by plating onto low-swarm agar ( $P$. mirabilis) and Mueller-Hinton agar (S. aureus) to enumerate the adhered bacteria per sample. The inoculum density was also verified at each time interval. Five replicate discs of each material were tested at each $\mathrm{pH}$ and for each time interval ${ }^{43}$.

Bacterial adherence to the prepared polymers was also assessed in an artificial urine (AU) medium as per the previously described method but with the use of AU solution, prepared using the composition described by Cox et al. (1987) in Table 5 instead of $\mathrm{pH} 7$ and pH 10 
PBS ${ }^{44}$. Two solutions (A and B) were prepared and mixed immediately before use to avoid precipitation of calcium phosphate in the form of brushite, which would lead to a corresponding reduction in the concentration of calcium and phosphate ions. $\mathrm{pH}$ of the resulting solution was adjusted to $\mathrm{pH} 6$ by the dropwise addition of $2 \mathrm{M} \mathrm{NaOH}$.

Table 5. Composition of artificial urine

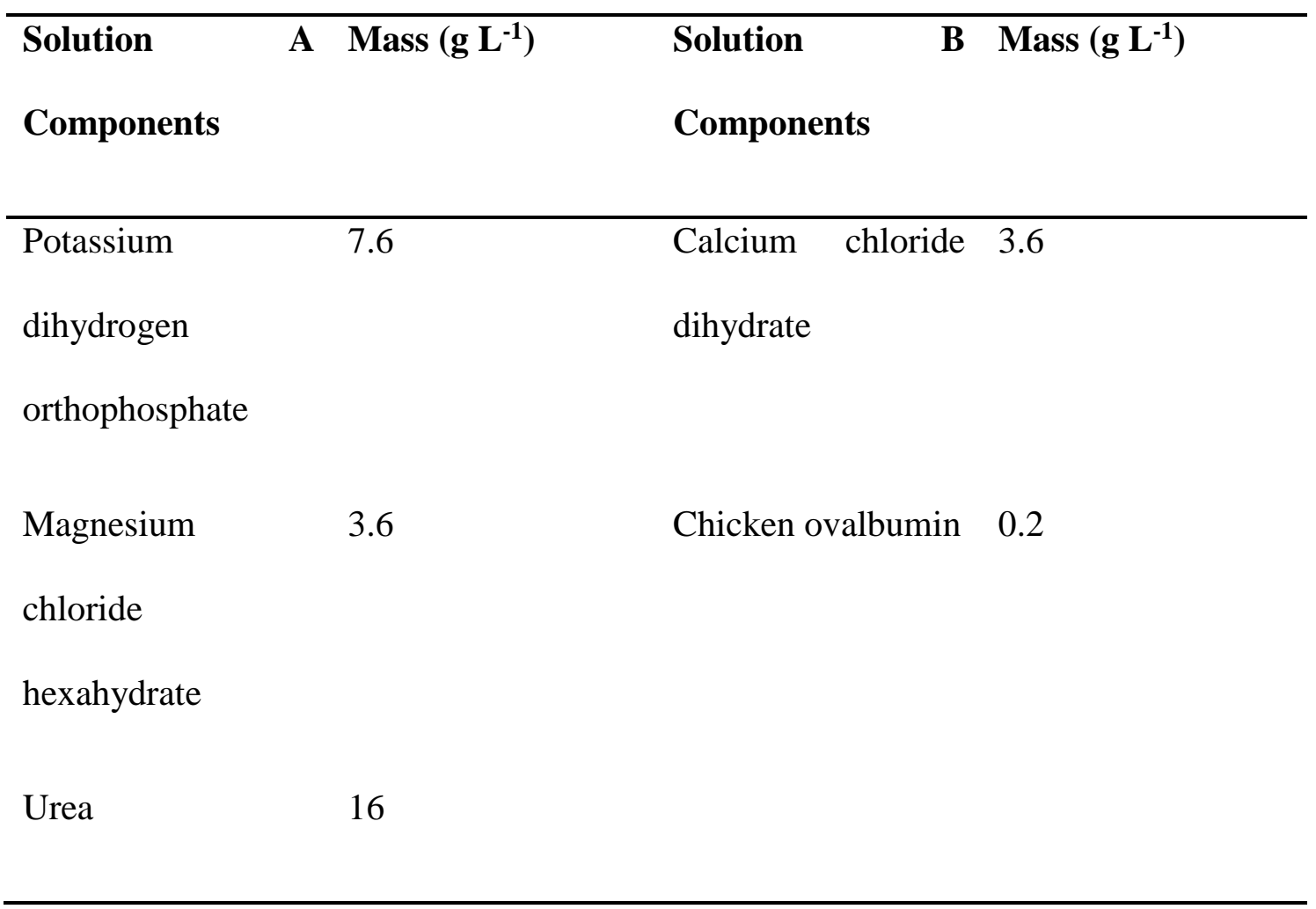

\section{Zones of bacterial growth inhibition}

Zones of $P$. mirabilis and $S$. aureus growth inhibition around the TX conjugate copolymers and $\mathrm{p}$ (HEMA) as a control were assessed by the standardised Kirby-Bauer disc diffusion method at $\mathrm{pH} 7$ and $\mathrm{pH} 10^{45}$. Inoculum $\left(1 \times 10^{8} \mathrm{cfumL}^{-1}, 100 \mu \mathrm{L}\right)$ was added to a test tube of molten MHA (pH 7 or $\mathrm{pH} 10,10 \mathrm{~mL}$ ), vortexed and then poured into a sterile petri dish. Once the agar had set and cooled, discs (10 $\mathrm{mm}$ in diameter), which had been pre-soaked in $\mathrm{pH} 7$ 
buffer for $24 \mathrm{~h}$, were placed in the centre of the inoculated plates and incubated at $37^{\circ} \mathrm{C}$ for 24 h. Each day the diameter of the inhibition zone with no bacterial growth, including the disc diameter, was measured. Any discs exhibiting zones of growth inhibition were transferred to freshly seeded plates and the process repeated daily until no further inhibition. Five replicates were assessed at each $\mathrm{pH}$ for both strains of bacteria.

\section{Statistical analysis}

Statistical differences in contact angles between p(HEMA) and the TX conjugate copolymers were analysed by a one-way analysis of variance (ANOVA), whereas the effect of $\mathrm{pH}$ and copolymerisation with the TX conjugate on equilibrium water contents, TX release, bacterial adherence and zones of bacterial growth inhibition were statistically analysed by a two-way ANOVA, followed by Tukey's honestly significant difference test for post-hoc comparisons between means of individual groups. For all analyses, differences were considered significant when $p<0.05$.

\section{Acknowledgements}

This work was financially supported by the Department for the Economy (Northern Ireland).

\section{Supporting Information}

Scheme S1: Mechanism of DCC-mediated esterification of TX.

Figure S1: FT-IR spectra of (i) TX, (ii) 2-carboxyethyl acrylate, and (iii) TX conjugate from (a) $1800-1500 \mathrm{~cm}^{-1}$ and (b) $4000-1000 \mathrm{~cm}^{-1}$. 
Figure S2. Schematic of the surfactant conjugate copolymer.

Figure S3: FT-IR spectra of (i) p(HEMA), (ii) 5TXC and (iii) 10TXC from (a) $1800-1300 \mathrm{~cm}^{-}$ 1 and (b) $4000-600 \mathrm{~cm}^{-1}$.

Figure S4: TX release at $\mathrm{pH} 7$ and $\mathrm{pH} 10$ modelled according to the Korsmeyer-Peppas model equation.

Table S1: Percentage and logarithmic reductions in adherence of $P$. mirabilis and S. aureus to 5TXC and 10TXC relative to control p(HEMA) following incubation in inoculated (a) TSBcontaining PBS and (b) AU.

\section{References}

1. Damodaran, V. B.; Murthy, N. S., Bio-inspired strategies for designing antifouling biomaterials. Biomater. Res. 2016, 20 (1), 18.

2. $\quad$ Greenhalgh, R.; Dempsey-Hibbert, N. C.; Whitehead, K. A., Antimicrobial strategies to reduce polymer biomaterial infections and their economic implications and considerations. Int. Biodeterior. Biodegradation 2019, 136, 1-14.

3. Stickler, D. J., Clinical complications of urinary catheters caused by crystalline biofilms: something needs to be done. J. Intern. Med. 2014, 276 (2), 120-129.

4. Campoccia, D.; Montanaro, L.; Arciola, C. R., A review of the biomaterials technologies for infection-resistant surfaces. Biomaterials 2013, 34 (34), 8533-8554.

5. Zilberman, M.; Elsner, J., Antibiotic-eluting medical devices for various applications. J. Control. Release 2008, 130 (3), 202-215.

6. Campoccia, D.; Montanaro, L.; Speziale, P.; Arciola, C., Antibiotic-loaded biomaterials and the risks for the spread of antibiotic resistance following their prophylactic and therapeutic clinical use. Biomaterials 2010, 31 (25), 6363-6377.

7. McCoy, C. P.; Brady, C.; Cowley, J.; McGlinchey, S.; McGoldrick, N.; Kinnear, D., Triggered drug delivery from biomaterials. Expert Opin. Drug Deliv. 2010, 7 (5), 605616.

8. Irwin, N. J.; McCoy, C. P.; Jones, D. S.; Gorman, S. P., Infection-responsive drug delivery from urinary biomaterials controlled by a novel kinetic and thermodynamic approach. Pharm. Res. 2013, 30 (3), 857-865.

9. $\quad$ McCoy, C. P.; Irwin, N. J.; Brady, C.; Jones, D. S.; Carson, L.; Andrews, G. P.; Gorman, S. P., An infection-responsive approach to reduce bacterial adhesion in urinary biomaterials. Mol. Pharm. 2016, 13 (8), 2817-2822.

10. Safdar, N.; Codispoti, N.; Purvis, S.; Knobloch, M. J., Patient perspectives on indwelling urinary catheter use in the hospital. Am. J. Infect. Control 2016, 44 (3), e23-e24. 11. Stickler, D.; Lear, J.; Morris, N.; Macleod, S.; Downer, A.; Cadd, D., Observations on the adherence of Proteus mirabilis onto polymer surfaces. J. Appl. Microbiol. 2006, 100 (5), 1028-1033.

12. Stickler, D. J.; Morgan, S. D., Modulation of crystalline Proteus mirabilis biofilm development on urinary catheters. J. Med. Microbiol. 2006, 55 (5), 489-494. 
13. Jacobsen, S.; Stickler, D.; Mobley, H.; Shirtliff, M., Complicated catheter-associated urinary tract infections due to Escherichia coli and Proteus mirabilis. Clin. Microbiol. Rev. 2008, 21 (1), 26-59.

14. Stanton, T. B., A call for antibiotic alternatives research. Trends Microbiol. 2013, 21

(3), 111-113.

15. Van Hamme, J. D.; Singh, A.; Ward, O. P., Physiological aspects: Part 1 in a series of papers devoted to surfactants in microbiology and biotechnology. Biotechnol. Adv. 2006, 24 (6), 604-620.

16. Simoes, M.; Pereira, M. O.; Machado, I.; Simões, L. C.; Vieira, M., Comparative antibacterial potential of selected aldehyde-based biocides and surfactants against planktonic Pseudomonas fluorescens. J. Ind. Microbiol. Biotechnol. 2006, 33 (9), 741-749.

17. Bridgett, M.; Davies, M.; Denyer, S. P., Control of staphylococcal adhesion to polystyrene surfaces by polymer surface modification with surfactants. Biomaterials 1992, 13 (7), 411-416.

18. Jevtić, S.; Grujić, S.; Hrenović, J.; Rajić, N., Surfactant-modified clinoptilolite as a salicylate carrier, salicylate kinetic release and its antibacterial activity. Microporous Mesoporous Mater. 2012, 159, 30-35.

19. Salim, M. M.; Malek, N. A. N. N., Characterization and antibacterial activity of silver exchanged regenerated $\mathrm{NaY}$ zeolite from surfactant-modified $\mathrm{NaY}$ zeolite. Mater. Sci. Eng. C 2016, 59, 70-77.

20. Razatos, A.; Ong, Y. L.; Boulay, F.; Elbert, D. L.; Hubbell, J. A.; Sharma, M. M.; Georgiou, G., Force measurements between bacteria and poly(ethylene glycol)-coated surfaces. Langmuir 2000, 16 (24), 9155-9158.

21. Neises, B.; Steglich, W., Simple method for the esterification of carboxylic acids. Angew. Chem. Int. Ed. 1978, 17 (7), 522-524.

22. Coates, J., Interpretation of infrared spectra, a practical approach. In Encyclopedia of Analytical Chemistry, 1 ed.; Meyers, R. A., Ed. John Wiley and Sons Ltd.: Chichester, 2000; pp 10815-10837.

23. Nita, L. E.; Chiriac, A. P.; Nistor, M. T., Upon the emulsion polymerization of 2hydroxyethyl methacrylate with 3,9-divinyl-2,4,8,10-tetraoxaspiro[5.5]-undecane. Colloids Surf. A Physicochem. Eng. Asp. 2011, 381 (1-3), 111-117.

24. Aguilar-Morales, A. I.; Alamri, S.; Voisiat, B.; Kunze, T.; Lasagni, A. F., The Role of the Surface Nano-Roughness on the Wettability Performance of Microstructured Metallic Surface Using Direct Laser Interference Patterning. Materials 2019, 12 (17), 2737.

25. Wang, T.; Xie, M.; Abbasi, S.; Cheng, Z.; Liu, H.; Shen, W., High efficiency perovskite solar cells with tailorable surface wettability by surfactant. J. Power Sources 2020, 448, 227584.

26. Das, S.; Nguyen, Q.; Patil, P. D.; Yu, W.; Bonnecaze, R. T., Wettability alteration of calcite by nonionic surfactants. Langmuir 2018, 34 (36), 10650-10658.

27. Guo, J.; Zhang, L.; Liu, S.; Li, B., Effects of hydrophilic groups of nonionic surfactants on the wettability of lignite surface: Molecular dynamics simulation and experimental study. Fuel 2018, 231, 449-457.

28. Sailaja, G. S.; Ramesh, P.; Varma, H., Effect of surface functionalization on the physicomechanical properties of a novel biofunctional copolymer. J. Appl. Polym. Sci. 2011, 121 (6), 3509-3515.

29. Gupta, P.; Vermani, K.; Garg, S., Hydrogels: from controlled release to pHresponsive drug delivery. Drug Discov. Today 2002, 7 (10), 569-579.

30. Lauridsen, M.; Hansen, S. H.; Jaroszewski, J. W.; Cornett, C., Human urine as test material in H-1 NMR-based metabonomics: Recommendations for sample preparation and storage. Anal. Chem. 2007, 79 (3), 1181-1186. 
31. Khare, A. R.; Peppas, N. A., Release behavior of bioactive agents from $\mathrm{pH}$-sensitive hydrogels. J. Biomater. Sci. 1993, 4 (3), 275-289.

32. Stickler, D. J.; Feneley, R. C., The encrustation and blockage of long-term indwelling bladder catheters: a way forward in prevention and control. Spinal Cord 2010, 48 (11), 784790 .

33. Nejadnik, M. R.; van der Mei, H. C.; Norde, W.; Busscher, H. J., Bacterial adhesion and growth on a polymer brush-coating. Biomaterials 2008, 29 (30), 4117-4121.

34. Yan, S.; Song, L.; Luan, S.; Xin, Z.; Du, S.; Shi, H.; Yuan, S.; Yang, Y.; Yin, J., A hierarchical polymer brush coating with dual-function antibacterial capability. Colloids Surf. B. 2017, 150, 250-260.

35. Hamoud, R.; Zimmermann, S.; Reichling, J.; Wink, M., Synergistic interactions in two-drug and three-drug combinations (thymol, EDTA and vancomycin) against multi drug resistant bacteria including E. coli. Phytomedicine 2014, 21 (4), 443-447.

36. Rocha, S. P. D.; Pelayo, J. S.; Elias, W. P., Fimbriae of uropathogenic Proteus mirabilis. FEMS Immunol. Med. Microbiol. 2007, 51 (1), 1-7.

37. Belas, R.; Schneider, R.; Melch, M., Characterization of proteus mirabilisprecocious swarming mutants: Identification of rsba, encoding a regulator of swarming behavior. $J$.

Bacteriol. 1998, 180 (23), 6126-6139.

38. Maldonado-Codina, C.; Morgan, P. B., In vitro water wettability of silicone hydrogel contact lenses determined using the sessile drop and captive bubble techniques. J. Biomed.

Mater. Res. A. 2007, 83 (2), 496-502.

39. Koller, C. N.; Bauer, L. S.; Hollingworth, R. M., Characterization of the pHmediated solubility of Bacillus thuringiensis var. san diego native [delta]-endotoxin crystals. Biochem. Biophys. Res. Commun. 1992, 184 (2), 692-699.

40. Zahedi, P.; Lee, P. I., Solid molecular dispersions of poorly water-soluble drugs in poly(2-hydroxyethyl methacrylate) hydrogels. Eur. J. Pharm. Biopharm. 2007, 65 (3), 320328.

41. Korsmeyer, R. W.; Gurny, R.; Doelker, E.; Buri, P.; Peppas, N. A., Mechanisms of solute release from porous hydrophilic polymers. Int. J. Pharm. 1983, 15 (1), 25-35.

42. Costa, P.; Sousa Lobo, J. M., Modeling and comparison of dissolution profiles. Eur. J. Pharm. Sci. 2001, 13 (2), 123-133.

43. Irwin, N. J.; Bryant, M. G.; McCoy, C. P.; Trotter, J. L.; Turner, J., Multifunctional, low friction, antimicrobial approach for biomaterial surface enhancement. ACS Appl. Bio Mater. 2020, 3 (3), 1385-1393.

44. Cox, A. J.; Hukins, D. W. L.; Davies, K. E.; Irlam, J. C.; Sutton, T. M., An automated technique for in vitro assessment of the susceptibility of urinary catheter materials to encrustation. Eng. Med. 1987, 16 (1), 37.

45. Bauer, A. W.; Kirby, W. M.; Sherris, J. C.; Turck, M., Antibiotic susceptibility testing by a standardized single disk method. Am. J. Clin. Pathol. 1966, 45 (4), 493-496. 


\section{For Table of Contents Use Only}

Infection-triggered, self-cleaning surfaces with on-demand cleavage of surface-localised surfactant moieties

Nicola J. Irwin*, Johann L. Trotter, Louise Carson, Colin P. McCoy

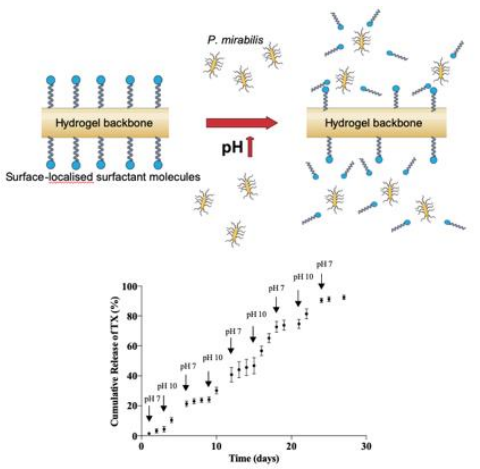

